\title{
Space, Gravity and the Physiology of Aging: Parallel or Convergent Disciplines? A Mini-Review
}

\author{
Joan Vernikos ${ }^{\text {a }}$ Victor S. Schneider ${ }^{b}$ \\ a Life Sciences, NASA and Thirdage Ilc, Culpeper, Va., ${ }^{b}$ Office of the Chief Health and Medical Officer \\ and Explorations Systems Mission Directorate, NASA, Washington, D.C., and Uniformed Services University, \\ Bethesda, Md., USA
}

\section{Key Words}

Gravitational physiology · Mechanotransduction •

Accelerated aging models $\cdot$ Rehabilitation

\begin{abstract}
The abnormal physiology that manifests itself in healthy humans during their adaptation to the microgravity of space has all the features of accelerated aging. The mechano-skeletal and vestibulo-neuromuscular stimuli which are below threshold in space, result in an overall greater than 10-fold more rapid onset and time course of muscle and bone atrophy in space and the development of balance and coordination problems on return to Earth than occur with aging. Similarly, the loss of functional capacity of the cardiovascular system that results in space and continuous bed rest is over 10 times faster than in the course of aging. Deconditioning in space from gravity deprivation has brought attention to the medical hazards of deconditioning on Earth from gravity withdrawal as in sedentary aging. Though seemingly reversible after periods of 6 months in space or its ground analog of bed rest, it remains to be seen whether that will be so after longer exposures. Both adaptation to space and aging do not merely parallel but converge as disorders of mechanotransduction. Like spaceflight, its analog bed rest telescopes the changes observed with aging and serves as a useful clinical model for the study of age-related deconditioning. The
\end{abstract}

convergence of the disciplines of aging, along with gravitational and space physiology is advancing the understanding and prevention of modern lifestyle medical disorders.

Copyright $\odot 2009$ S. Karger AG, Basel

\section{Introduction}

Aging and adaptation to spaceflight in young healthy astronauts are similar in the way they affect human physiology. Both aging and living in space induce the decline not of a single system but a composite of almost every body system reaching critical levels of functionality at different times. The time course of this decline with aging [1] depends on variables such as genetics, development, metabolism, lifestyle and others we may have as yet not identified. Both involve complex multifactorial processes with two distinct differences: in the case of spaceflight, the influence of Earth's gravity is below a physiological threshold and, as far as we can tell from the short durations of up to 6 months - or 14 months in the case of one cosmonaut - general health appears to have recovered, though systematic recovery data are not available. Rehabilitation procedures have also not been standardized.

The Space Race that started in the late fifties between the Soviet Union and the United States first made it pos-

\section{KARGER \\ Fax +4161306 1234 \\ E-Mail karger@karger.ch}

www.karger.com (c) 2009 S. Karger AG, Basel

0304-324X/10/0562-0157\$26.00/0

Accessible online at:

www.karger.com/ger
Dr. Joan Vernikos

Thirdage llc

2028 Golf Drive

Culpeper, VA 22701 (USA)

Tel. +1 540829 2541, E-Mail dr.joan@joanvernikos.com 
sible to explore the role of gravity in human physiology by allowing humans to live in an environment where gravity $(G)$ was reduced to what appears to be below its physiological threshold $-10^{-5} \mathrm{G}$. The answers led to an astonishing insight on the role of gravity in physiology on Earth that arose from studying healthy humans living in the microgravity of space. What was totally unexpected was a possible link between gravity and aging.

\section{Similar Physiologic Signs and Symptoms}

Disturbed regulation of blood pressure evidenced by orthostatic hypotension $(\mathrm{OH})$ after flight turned out to be the first of a number of physiologic signs $[2,3]$. Clinical observations led to the now well-documented loss of calcium and osteopenia in space. Dietrick et al. [4] questioned whether the bone loss in patients suffering from polio was the result of the infectious disease or of the immobilization due to the paralysis. Their studies in healthy students immobilized in bed in lower body casts showed that inactivity caused severe calcium and bone loss. Whedon hypothesized that astronauts would show similar bone and calcium loss in space, where without gravity their bodies would become virtually inactive. This theory was tested on Gemini VII in 1964, the first mission to collect in-flight samples from its two astronauts over 14 days. It brought attention to increased calcium excretion, raising concern that microgravity may be causing bone calcium loss [5]. Additionally, weight loss during flight and rapid recovery on return, suggesting it was due to fluid loss, led to studies on fluid and electrolyte regulation particularly as they related to the postflight $\mathrm{OH}$ $[6,7]$.

Pre- and postflight testing including bone density measurements provided important documentation $[2,3]$. Yet, it was not until the 1970s, when three sequential Skylab missions of increasing duration $(28,56$ and 84 days) with three astronauts in each, that a wealth of data formed the foundation of space physiology $[2,3,7]$. As the results came in on negative calcium balance, bone density loss, muscle atrophy, cardiovascular and hematological changes, metabolic, endocrine, and disturbed sleep, medical observers commented that astronauts must be growing old faster in space since their symptoms were similar to those seen in the elderly. This conclusion was swiftly dismissed as soon as it was clear that astronauts recovered after returning to Earth. Yet the similarity of symptoms and the possibility that longer exposures to space may indeed accelerate aging remained a nagging concern [8].
With longer exposures to space research continued to document $[2,3]$ this array of signs and symptoms that are also seen with advancing years. Reduced plasma volume (PV), muscle mass and strength, aerobic exercise capacity, depressed immune responses, back pain and postflight vestibular, balance and coordination problems were substantiated $[2,3]$.

\section{Answers Came from Ground-Based Simulation Research}

There has been slow progress in space research because of the small numbers of astronauts and the operational difficulties of conducting research in microgravity. Through 2009 only about 500 space mission crewmembers have flown. Most missions, and therefore most data were obtained over 14 days or less. No two flights are the same, introducing variables such as shift work, the amount or type of exercise or extravehicular activity. In addition to mission duties, astronauts who are in excellent health and peak fitness before flight are asked to volunteer for multiple experimental protocols, often not the same on any one flight or any single astronaut, inevitably complicating data interpretation.

Ground simulation in healthy volunteers as well as nonhuman research were essential to provide the context for interpreting flight observations. It was the only way to tease out the influence of contributing factors and explore mechanisms in a controlled manner.

Lying continuously in head-down bed rest (HDBR) at $-6^{\circ} \mathrm{C}$ is now used as the model of choice [9]. Physiological changes in space and HDBR are remarkably similar [10]. HDBR induces a headward shift of fluids, unloads the body from its usual head to toe $G_{z}$ weight-bearing position, and precludes changes in posture, leading to unloading and possibly inactivity as well $[2,3,11]$. The influence of the gravity vector is exerted only across the chest in the $G_{x}$ direction. By inducing many of the changes observed in spaceflight, HDBR affords a means of mapping the time course of these changes and exploring mechanisms under more controlled conditions $[10,11]$.

\section{Differences}

Expecting all the processes involved in the changes common to spaceflight, bed rest and aging to be identical can be misleading since the physiologic results may be multifactorial with some variables and time course not 
the same. The responses to spaceflight or bed rest have relatively clean and acute signals of gravity transition from $1 G_{z}$ to either a change in the $G$ vector or to microG. In space or on the ground, these adaptations have been measured reliably for the most part for no more than a 6 -month period. In contrast, there is no apparent sharp initiating stimulus to aging, which is considered an ongoing process defined by time. Longitudinal aging studies, for instance, do not begin at birth or at the peak of puberty but more likely in young adulthood [12]. What in fact is being compared is the early response (days/months) to a relatively acute stimulus - microgravity or replacement of $1 G_{z}$ with $G_{x}$ - with physiologic function at a slice of time on the aging curve mostly at a much later time point (years/decades). In the case of aging, the stimulus removed is the increasingly reduced use of $G_{z}$ over a lifetime. Inactivity and unloading are the primary consequences of reduced $\mathrm{G}_{\mathrm{z}}$ use. Whereas the continuous physiologic responses to the infinite variety of acceleration, touch, pressure and other daily mechanical stimuli are important components to the maintenance of health, the gradual, progressive withdrawal of these activities is the hallmark of aging.

There is much about the physiology of gravity that has yet to be discovered. For example, nothing is known about the influence of gravity on longevity or on its underlying genetic mechanisms.

Furthermore, it must be obvious that spaceflight and HDBR are not identical either. The primary difference is that the early neurovestibular responses differ significantly since volunteers in bed do not experience the nausea that is a prompt response to microgravity $[2,3]$. Nevertheless, balance and coordination problems follow both conditions. The immunosuppression and viral reactivation seen in space appears to be stress related rather than due to microgravity [13]. However, gravity may also play a role as suggested by evidence of increased virulence of bacteria in vitro, of resistance to antibiotics and the toxicity of salmonella in mice following a 2-week spaceflight [14].

Initial diuresis and natriuresis is a consistent response to head HDBR that precedes the decrease in PV $[10,11]$. It is not evident on the first day of spaceflight even though both conditions result in similar decreases in PV. In the case of spaceflight, astronauts avoid drinking before launch, are on their backs awaiting launch during $2 \mathrm{~h}$ of countdown, experience hypergravity $\left(G_{\mathrm{x}}\right)$ during launch and varying degrees of nausea, particularly on the first day, making fluid and electrolyte data suspect.

Perhaps the most significant difference between spaceflight and its bed rest analog with aging is the telescopic compression of the time course of the observed changes. Spaceflight and to a somewhat lesser extent HDBR accelerate the onset and the rate of the observed changes $[2,3]$. This is probably due to the acute and sustained withdrawal of the gravity vector signal in space or its analog compared to the very gradual reduction of the use of gravity in the form of increasing inactivity over decades of aging.

The effects of living in the microgravity of space, just as aging, probably involve every organ of the body. Those changes and systems that most obviously are affected in both conditions lend themselves to further study as to whether they are merely similar or share common processes. Another way of addressing similarities and differences is to compare the recovery process in the three conditions as well as the effectiveness across space, HDBR or aging of a countermeasure or treatment to the extent that such data are available.

In space and in HDBR, the cause of the resulting changes is known because they result from the variation in the gravity level or vector. It is tempting to hypothesize that the causative stimulus for the appearance of similar changes over a lifetime is also gravity related, albeit graduated over time. The purpose of this review is to present comparative data from selected examples and stimulate an important ongoing discussion and further directed research.

\section{Cardiovascular Control}

Spaceflight or its ground analog - HDBR - are characterized by diminished cardiac function and mass $[15$, 16]. The initial trigger to this effect is the fluid shift from the lower to the upper body that results in upper body blood volume expansion. This stimulates central volume carotid, aortic and cardiac receptors inducing a transient increase in diuresis and natriuresis with sustained $2-4 \%$ reduction of body mass and 6-15\% of PV [17]. Reduced PV is followed by decreased heart size, cardiac filling, stroke volume, cardiac output, and aerobic capacity. The sensitivity of carotid-cardiac baroreflexes is significantly decreased within 10-12 days of HDBR or spaceflight [18].

On return to Earth's gravity or standing after bed rest, this cardiovascular deconditioning leads to $\mathrm{OH}$. Once assumed to have been due to changes in sympathetic neuronal sensitivity, studies both in space and in HDBR have shown that the response to sympathetic nerve stimulation remains unchanged [19]. Moreover, the $\mathrm{OH}$ as well 
as reduced baroreflex sensitivity can be prevented in volunteers after 2 weeks of bed rest by acutely restoring PV [20], indicating that PV is the critical element in the development of $\mathrm{OH}$.

Aging and deconditioning in space or HDBR are similar in many respects. Progressive hypovolemia and reduced aerobic capacity is also seen with aging. $\mathrm{OH}$ becomes evident particularly with dehydration, heat or mild illness. There is an age-related reduction in the sensitivity of the arterial baroreflex [21] not unlike what occurs in space and bed rest. The calculated loss of cardiovascular functional capacity in 3 weeks of HDBR as measured by $\mathrm{VO} 2_{\max }$ and cardiac output is equivalent to that seen in the same subjects after 30-40 years of aging [22].

Decreased heart size is seen in space, HDBR and aging and the nature of the changes appear to be similar. Data obtained from magnetic resonance imaging measurements show a $14 \%$ reduction in left ventricular mass during spaceflight pointing to cardiac remodeling that would compromise myocardial function [23]. Similar evidence of cardiac atrophy was found in bed rest [23].

In healthy sedentary aging, abnormalities of these same diastolic properties result - the heart gets smaller, but also stiffer with age, left ventricular relaxation (LVR) is slower and left ventricular compliance is decreased [24]. The metabolic theory of cardiac stiffening proposes that 'the metabolic consequences of sedentary aging relative insulin resistance and excess caloric intake relative to expenditure, with or without obesity - lead to "lipotoxicity" and the accumulation of abnormal metabolites such as triglycerides and advanced glycation end products (AGEs) form cross-links that separately or together contribute to the stiffening of the aged heart' [25]. The accumulation of AGEs with long-lived proteins such as collagen form complex cross-linked proteins resulting in myocardial or vascular stiffening. Current research is designed to provide evidence that this mechanism may also occur in astronauts deconditioned in space. This is being done by measuring intracardiac triglyceride infiltration using MR spectroscopy as well as using delayed enhancement to detect subtle degrees of cardiac fibrosis [Levine, pers. commun.].

It is not only the heart muscle that changes with deconditioning. Arteries are believed to respond to smaller volume by constricting to keep the blood flowing since they no longer see the shear forces that stimulate arterial walls. Endothelial lining, sensitive to blood flow-generated shear stress, responds with structural wall remodeling which, as in the heart, is affected by the lipid/protein and inflammation environment conducive to the development of local or systemic damage. Rats deconditioned by aging [26] or hind limb unloading show diminished microvascular endothelial function. Rapid, dramatic thinning, weakening and stiffening of arteriolar walls appear when shear forces and the resulting chemical signals that keep them responsive are reduced $[26,27]$.

Normal aging generally leads to reduced physical activity in humans. Or is it that reduced physical activity leads to aging symptoms? Could the changes in left ventricular morphology be brought on by lifelong physical deconditioning and chronic reduced volume or are they specific to the aging process? Studies in master athletes and sedentary seniors show that loss in left ventricular compliance can be completely prevented with lifelong aerobic endurance exercise [28]. Similarly, aerobic exercise such as pedaling on a horizontal cycle ergometer (in HDBR) or walking or jogging on a treadmill in space while tethered to the floor or the treadmill with elastic straps has been shown to maintain respiratory work capacity $[2,3,10]$.

In contrast, aerobic exercise has little effect on LVR in sedentary seniors, possibly due to the basic differences in cellular regulation of the two processes. LVR, involving $\mathrm{Ca}^{2+}$ handling, appears resistant to aerobic training and may be specific to the aging process [29].

\section{The Musculoskeletal System}

Muscle strength, energy balance and bone health influence the ability to perform physical tasks of daily life. The ease with which these tasks can be performed determines the degree of independence an individual may maintain with advancing age. Even in healthy adults of advanced age, the capacity to perform these tasks is reduced, with increased incidence of disability and reduced quality of life. Muscle, bone and their metabolic requirements must be considered as a single entity.

In space, the body has mass but not weight. Without gravity, blood supply to the legs is reduced $[2,3]$. An astronaut does not walk as on Earth so that neuromuscular innervation to the legs is minimally used; leg muscles do not have to bear the body's load or contract as much with the result that they atrophy $[2,3]$. This is particularly true for postural muscles like the soleus, but all leg muscles are affected whereas arm muscles that continue to be used hardly atrophy. The average loss of bone and muscle with age is about $1 \%$ per year starting from peak development at about 24-30 years of age with significant cumulative 
loss with advancing years. Astronauts in space lose about $1 \%$ of muscle a month and generally about $1.8-2 \%$ of bone during that same period. Similar changes in the rate of loss are measured during bed rest [29-36].

\section{Bone}

During the millions of years of evolution of vertebrate animals, the human skeleton eventually stood erect, working against the force of gravity. Bone's major role is to support the body and to serve the mechanical needs of the body to move. It grows by increasing in length during early growth through the closure of the epiphyses at late puberty. The size and shape of the mature skeleton is greatly influenced by the amount of activity and forces applied to it within the $1 \mathrm{G}$ environment. After development peaks bone is lost steadily until the appearance later in life of fragility or osteoporosis [33, 34].

Bone responds to loading such as body weight and to the tension that muscles, tendons and ligaments apply as the muscles contract. Blood flow, neuromuscular input as well as endocrine and nutritional factors all converge to maintain bone healthy and strong [35]. Bone mass and density have primarily been the standard measures, but it is increasingly evident that architectural integrity is crucial [36].

From the start of manned spaceflight in the 1960s, it rapidly became apparent that urinary calcium increased and bone radio-densitometry showed mineral density loss. In the 1970s, the longer Skylab missions showed a progressive negative calcium balance that plateaued at $-200 \mathrm{mg} /$ day and up to $33 \%$ loss of the calcaneus, the heel bone. Months after returning from the flight, heel bone density was still significantly lower than normal $[2,3]$.

As measurement technology tools improved, so did bone research. Computer tomography used to measure bone mineral density (BMD) in 4 cosmonauts who spent up to 7 months on the Russian space station Mir showed all had lost BMD mainly from the posterior vertebra, and dual X-ray photon absorptiometry showed loss in the spine, femoral neck, trochanter and pelvis of about 1$1.6 \%$ per month and $0.3-0.4 \%$ per month in the legs and the whole body, but no loss at all in the forearm in 1-and 6-month missions [37].

A 4-year study [36-38] of the long-term effects of weightlessness in the microgravity of space on the bones of the ISS crew showed that on average they lost $11 \%$ (range 0-24\%) [Schneider pers. commun.] of their total hip bone mass over the course of 4-6 months. Thus, newer techniques and longer durations in space are revealing that unlike previously thought, living in space accelerates

Space, Gravity and the Physiology of Aging
20 -fold the normal rate of bone loss that happens with aging. The rate and extent of bone loss were sufficient to raise concern for an increased risk of fracture when astronauts return to gravity and resume their usual activity [36].

The study also found that a year after they had returned to Earth, much of their bone had been replaced, although the bone structure and density had not returned to normal. Hip strength had not recovered, although it had increased slightly compared to what it was when they landed. 'The magnitudes of the reductions in proximal femoral strength were comparable to estimated lifetime losses associated with aging' [36]. Studies of aging show that bone size increases as a compensation for lost bone mass. One-year measurements in astronauts after flight were also consistent with an increase in bone size, although this increase in bone was not enough to result in full recovery of the hip bone strength. Will these structural changes recover or are they permanent?

In trying to assess bone loss with aging, space or bed rest, ultimately what matters is how bone structure is affected. ISS crew members lost both trabecular (inner spongy layer) and cortical (outer layer) bone in the hip, whereas bone loss with aging usually occurs mostly at the inner bone layers [36-38]. There appeared to be a gradient of mineral loss beginning at the lumbar spine and increasing in the hip, reinforcing the role of gravity in this pattern in the astronauts. After spaceflight, the long compensatory period for recovery may be due to a small amount of periosteal growth that may partially serve to maintain the cross-sectional area of bone to maintain strength, but whose architecture is abnormal as compared to younger bone.

Studies using bed rest have found remarkably similar losses in bone as in space $[39,40]$. Bone mineral content loss in the tibia of healthy adult males after 90 days of bed rest largely recovered within 1 year and was estimated to be fully regained within 2 years with a structured exercise, drug-free rehabilitation protocol. Bone formation and resorption markers had returned to baseline values. Functional rehabilitation and resumption of impact sport activities appeared to precede bone recovery. The authors point out that 'the initial reaccrual rate of bone was remarkably high, comparable to the accrual of bone mass during the prepubertal growth spurt' suggesting that the adult skeleton is highly capable of responding and adapting to mechanical stimuli $[41,42]$.

Several studies suggest that the rate of the mechanical strain is more important to bone formation than static 
loading or the magnitude of the strain. Bone exposed to vibration or exercise respond better to faster stimuli. Bone cells exposed to vibration stress over a wide range of frequencies from 5 to $100 \mathrm{~Hz}$ released more nitric oxide (NO) at the highest acceleration rate [43]. The increase in $\mathrm{NO}$ - the signaling molecule in osteocytes - correlated linearly to the rate of fluid shear stress in the bone cell canaliculi. This resulted through the expression of several mechanosensitive genes such as ALP, runx2, osteomodulin, parathyroid hormone receptorl and osteoglycin. In vivo studies provided evidence that the rate of strain or movement is more important to building bone than amplitude or power required. Low-magnitude (less than 10 microstrains), high-frequency $(10-100 \mathrm{~Hz})$ loading stimulates bone growth and decreases disuse osteoporosis $[44,45]$.

\section{Muscle}

Aging, living in space or lying in bed leads to the deterioration of muscle quantity and quality. Muscle mass, strength and power are lost due to a decline in neuromuscular transmission, muscle structure, function, metabolism and performance [46]. Known as sarcopenia in the elderly, it is a considerable public health problem. It is this deterioration with age that has been presumed to lead to the gradual slowing of movement and frailty that often lead to the increased risk of injury and loss of independence [47].

Experience with fit, healthy young astronauts in space and even more so of similarly healthy young adults in bed has led us to the opposite conclusion - that it is the reduced influence of gravity on the body, either in space or through inactivity, unloading and diminished posture change that brings on muscle atrophy and the decline in strength [48].

Furthermore, the current exercise programs in space seem to be only partially effective in counteracting the course of these changes $[49,50]$. It is not known how severe these changes would have been without any exercise because from the beginning of the space program astronauts and cosmonauts have taken some form of exercise - mostly using stretch bands, a treadmill, bicycle ergometer or a variety of resistive devices.

Not unlike bone, muscle atrophy is evident predominantly in the lower body sparing the upper body and affecting mostly postural muscles as well as those supporting the spinal cord and neck $[48,49]$. This results in painful compression and back pain on return to Earth's gravity $[2,3]$. As might be expected, tendons and ligaments are similarly affected, diminishing their support- ing value to bone and joints. The French flight surgeon testing the cosmonauts who had spent 4.5-7 months on Mir commented that they were all flat-footed on return [Guell, pers. commun.].

Much has been learned about the changes produced in the adaptive physiology of muscle to this abnormal weightless environment. The study of 9 astronauts who spent 6 months on the ISS encapsulates how microgravity affects muscle [49]. These astronauts had access to a running treadmill, cycle ergometer and resistance exercise device. The regimen varied among the participants with aerobic exercise performed about $5 \mathrm{~h} /$ week at a moderate intensity and resistance exercise 3-6 days/week involving multiple lower leg exercises. The volume of the calf muscle decreased by $13 \%$ over the 6 months with most of the atrophy $(-15 \%)$ occurring in the soleus as compared to the gastrocnemius $(-10 \%)$. Peak power was $32 \%$ lower after spaceflight. Across the velocity spectrum, force-velocity characteristics were reduced by -20 to $29 \%$. There was a shift in the myosin heavy chain (MHC) fiber type of $12-17 \%$ in both the soleus and the gastrocnemius with a decrease in MHC I and redistribution among the faster phenotypes. In other words, together with the decrease in muscle mass and performance, there was a shift from slow to fast fiber type in both muscles since weight-bearing posture muscle was no longer needed. These are all characteristics associated with unloading of any kind in humans.

In age-related sarcopenia, spaceflight or HDBR, muscle atrophy is reversible when appropriate exercise is added to daily activities $[51,52]$. Reinforcing the probable dependence of bone on muscle was the observation that calf muscle cross-section during recovery from 120 days of bed rest preceded the recovery of bone, appeared tightly regulated and generally followed neuromuscular recovery [39].

Moreover, Booth et al. [53] put forth the hypothesis that natural selection of gene expression supports a physically active lifestyle as it evolved from the days when survival depended on physical activity for food. Uncoupling of gene and lifestyle implies that a sedentary lifestyle would result in abnormal gene expression 'causing premature death from chronic diseases produced by physical inactivity.' Therefore 'genes evolved with the expectation of requiring a certain threshold of physical activity for normal physiologic gene expression and thus habitual exercise in sedentary cultures restores homeostatic mechanisms towards the normal physiologic range'. Booth's theory is impressive because it is logical. 
The fact that the current exercise programs are only partially effective in space points to the crucial role of the loading factor - gravity - in this formula.

\section{Metabolism}

The abundance of food and decreasing work required to accomplish life's activities or the increasing sedentary lifestyle of older people brings the discussion inevitably to the metabolic consequences of inactivity or gravity deprivation. Although we may consume less than our forbearers, Booth argues that nevertheless we consume more than we need in relation to modern day sedentary lifestyle. He posits that 'the combination of continuous food abundance and physical inactivity eliminates the evolutionarily programmed biochemical cycles emanating from feast-famine and physical activity-rest cycles, which in turn abrogates the cycling of certain metabolic processes ultimately arriving at metabolic derangements such as obesity and type 2 diabetes' [54].

Although humans obviously do not become obese in space or bed rest, energy requirements are reduced to the basal metabolic rate plus a small percentage of calories needed for small residual movements and thermogenesis. The relative level of fat increases with decreased muscle and bone mass [55], which is an important factor in prediabetes [56]. With loss of muscle tissue, there is a negative protein balance which in short studies of 7-14 days bed rest begins with an acute decrease in protein synthesis followed by increased breakdown [57]. There is a shift in body composition as fat increases in the body $[56,58$, 59].

In addition, symptoms of a prediabetic state appear as significantly reduced glucose tolerance, hyperinsulinemia in response to a carbohydrate meal and insulin resistance of muscle [10]. Increased C-reactive protein blood levels and decreased glucose transporter protein (GLUT-4) levels in the gastrocnemius muscle have been measured in bed rest in as little as 6 days [60]. In contrast, caloric restriction has been shown in many species including humans in bed rest to prevent the increase in Creactive protein and the inflammatory response. It should be noted that studies in mice showed that low-amplitude/ high-frequency vibration that is effective in preventing bone loss also resulted in a substantial decrease in fat cell production, triglycerides and free fatty acids, all risk factors for type 2 diabetes and cardiomyopathy [61].

Space and bed rest also affect the absorption of nutrients from the gastrointestinal tract. Notably the decreased production of vitamin $\mathrm{D}$, less calcium absorption together with an increased salt appetite further aggravate bone loss [62-64]. Increased calcium urinary excretion together with the relative dehydration in space, increase the risk of kidney stone formation $[65,66]$. Fourteen astronaut and multiple cosmonaut stone incidents have been reported, one during the flight. The risk of kidney stones appears higher immediately after flight [66].

\section{Central and Peripheral Nervous System}

Motor coordination and sensory organization of postural control are affected by spaceflight and aging. These different aspects of control interact but may be affected differently in each individual depending on their particular characteristics and history of muscle strength, adaptability, intact senses, athletic ability, prior experience and what is required of them. Each therefore will be unstable for different reasons and therefore will require different interventions to accelerate compensation.

Some individuals compensate by relying primarily on somatosensory sensation while others rely on visual information. Proprioception is the most important sense for control of equilibrium since it is impossible to balance against gravity without it. Vestibular information is probably more important for the orientation of head and trunk than for control of the center of gravity for equilibrium. Postural control requires intact cerebellum and basal ganglia, which are often suboptimal in the elderly [67]. The nervous system needs to extract and interpret the relevant sensory information to orient the body with respect to relevant cues. This complex integration is by its nature variable. To the extent that the absence of gravity as a single variable in young and older subjects can help shed light on the issues of postural stability in the elderly, spaceflight and to a lesser extent its HDBR analog may provide a useful tool.

Living in space for as little as 9 days accelerates problems of equilibrium on standing, walking and coordination on return to Earth. Readaptation to Earth after flights of 4-9 days began immediately on landing, proceeded rapidly for the first 10-12 $\mathrm{h}$ and then more slowly for 2-4 days until preflight stability was reachieved. [68]. Similar problems are measurable after 30-90 days in bed rest [69]. With longer stays in bed or in space, the symptoms are more severe and take longer to recover. The modified commercial dynamic posturography system used to induce reliance primarily on vestibular function in astronauts was used to test 280 members of the Baltimore Longitudinal Aging Study run by the National Institute on Aging [70]. With eyes closed on this platform 
astronauts complain of having no sensation of falling. The test provides an early sign of balance deficits [71].

Increased sensitivity and tenderness of the soles of the feet is another feature seen after spaceflight, bed rest or with aging [71]. Sometimes ignored as unimportant, those who suffer from them face challenges such as walking across uneven terrain, negotiating obstacles in their path, driving a car or merely getting out of bed after a hip or femur fracture even after the fracture has healed. Other senses such as taste and smell are affected in all three groups as is peripheral vision when combined with movement [67-69].

Disturbed sleep and biological rhythms are a frequent complaint with advancing years as well as in astronauts and cosmonauts in space [72]. A possible link to a common mechanism between a lack of postural changes, activity-rest cycles, cycling of metabolic processes and overall inactivity with disturbed sleep is implied by the finding that young adults in bed also show reduced amplitude of diurnal excursions and shifting rhythms resulting in nocturnal diuresis. Body rhythms begin to lose their synchronization after as little as 10 days in bed, and the disruption reaches its height after 22-24 days [73]. Measurements in a single cosmonaut on Mir showed the complete disappearance of the body temperature rhythm after 3 months in space [74].

\section{Summary and Concluding Remarks}

The physiological responses to space and aging are characterized by problems of mechanotransduction. In space, the weighting of the body by Earth's gravity is absent, resulting in deconditioning from gravity deprivation. On Earth, similar changes result in deconditioning from gravity withdrawal - a sedentary lifestyle in the presence of gravity. Both result in changes associated with premature aging.

As in space, mechanical loading, mechanical forces and their relationship to cellular events affect the 'aging' of connective tissue or its loss [75]. In both cases, there is downregulation of mechanotransduction-mechanochemical transduction. From birth, mechanical forces, provided primarily by gravity, are crucial to normal development and evolution of the extracellular matrixes found in connective tissue. As body mass and its weight - a function of the gravity we live in - increases, musculoskeletal tissues and other extracellular matrixes adapt their size to meet increasing mechanical demands. With age, reduced use of gravity through decreased movement and acceleration, or living in space in reduced gravity, result in similar changes in body composition, metabolism and damage to musculoskeletal, cardiovascular and connective tissue.

Ingber's tensegrity theory and research [76] provides the framework for understanding how external and internal mechanical forces influence biological control at the molecular and cellular levels. His work reveals that 'molecules, cells, tissues, organs, and our entire bodies use tensegrity architecture to mechanically stabilize their shape, and to seamlessly integrate structure and function at all size scales.' In this way, it explains how at a mechanistic level intermittent mechanical forces applied externally such as vibration $[45,61]$, movement or exercise [28, 50], centrifugation [48], push or pull or intermittent tension [77] can influence cell and tissue growth, biochemistry and physiology.

Those who provide care to space travelers have much to learn from the study of the physiology of aging. Similarly, gerontologists and rehabilitation specialists can benefit from stepping back to consider the physiological changes of aging primarily as a disorder of mechanotransduction.

Medical and surgical advances have contributed to the extension of life. Yet technological inventions encourage an increasingly sedentary lifestyle. Deconditioning has accelerated physical incapacitation with all its consequences.

Whether the dots between space and aging eventually converge, space and HDBR are useful tools for studying the physiology of aging. Equally, gravitational physiology may lead to useful insights to help delay or prevent the physical incapacitation that seems inevitable with living longer. The passage of time is inevitable. Improved quality of life is the goal.

References Appl Physiol 2003;95:1706-1716.

2 Nicogossian AEN, Huntoon CL, Pool SL: Space Physiology and Medicine. Philadelphia, Lea and Febiger, 1989, 1994.

3 Nicogossian AE, Parker JF: Space Physiology and Medicine. NASA SP-447, NAS 1.21:447, LC-82-23047. Washington, NASA, 1982.

$\checkmark 4$ Dietrick JE, Whedon GD, Shorr E, Toscani V, Davis VB: Effect of immobilization on metabolic and physiologic functions of normal men. Am J Med 1948;4:3-35.

5 Lutwak L, Whedon GD, Lachance PA, Reid M, Lipscomb H: Mineral, electrolyte and nitrogen balance studies of the GeminiVII fourteen-day orbital space flight. J Clin Endocrinol 1969;29:1140-1156. 
6 Hoffler GW, Johnson RL: Apollo flight crew cardiovascular evaluation; in Johnson RS, Dietlein F (eds): Biomedical Results of Apollo. NASA Special Report SP-368. Washington, NASA, 1975, pp 244-265.

7 Leach CS, Rambaut PC: Biomedical responses of the Skylab crewmen: an overview. NASA SP-377. Washington, NASA, 1977.

8 Vernikos J: Human physiology in space. Bioessays 1996;18:1029-1037.

$\checkmark 9$ Meck JV, Dreyer SA, Warren LE: Long duration head down bed rest: project overview, vital signs and fluid balance. Aviat Space Environ Med 2009;80(suppl 5):1-8.

10 Pavy-Le Traon A, Heer M, Naric MV, Rittweger J, Vernikos J: From space to earth: advances in human physiology from 20 years of bed rest studies (1986-2006) Eur J Appl Physiol 2007;101:143-194.

11 Sandler H, Vernikos J (eds): Inactivity: physiological effects. New York, Academic Press, 1986.

12 With the Passage of Time: The Baltimore Longitudinal Study of Aging. October 1993. National Institute on Aging, National Institutes of Health, Bethesda, Maryland. www. nia.nih.gov/HealthInformation/Publications/BLSA/01_why.htm.

13 Pierson DL, Mehta SK, Stowe RP: Reactivation of latent herpes viruses in astronauts; in Ader R: Psychoneuroimmunology, ed 4. Amsterdam, Elsevier, vol 1, chapter 40, pp 851-868, 2008

- 14 Wilson JW, Ott CM, Quick L, et al: Media ion composition controls regulatory and virulence response of Salmonella in spaceflight. PLoS One 2008;3:3923.

15 Mulvaugh, SL, Charles JB, Riddle JM, Rehbein TL, Bungo MW: Echocardiographic evaluation of the cardiovascular effects of short-duration spaceflight. J Clin Pharmacol 1991;31:1024-1026.

16 Levine BD, Lane LD, Watenpaugh DE, Gaffney FA, Buckey JC, Blomquist CG: Maximal exercise performance after adaptation to $\mathrm{mi}$ crogravity. J Appl Physiol 1996;81:686-694.

-17 Levine BD, Pawelczyk JA, Ertl AC, Cox JF, Zuckerman JH, Diedrich A, Biaggioni I: Human muscle sympathetic neural and hemodynamic responses to tilt following spaceflight. J Physiol 2002;538:331-334.

18 Convertino VA: Mechanisms of microgravity induced orthostatic intolerance: implications for effective countermeasures. J Gravit Physiol 2002;9:1-13.

19 Pawelczyk JA, Zuckerman JH, Blomquist CG, Levine BD: Regulation of muscle sympathetic nerve activity after bed rest deconditioning. Am J Physiol Heart Circ Physiol 2001;280:2230-2239.

20 Iwasaki K-I, Zhang R, Perhonen MA, Zuckerman JH, Levine BD: Reduced baroreflex control of heart period after bed rest is normalized by acute plasma volume restoration. Am J Physiol Regul Integr Comp Physiol 2004;287:1256-1262.
21 Ferrari AU, Radaeli A, Cantola M: Aging and the cardiovascular system. J Appl Physiol 2003;95:2591-2597.

22 McGavock JM, Hastings, Snell PG, McGuire DK, Pacini EL, Levine BD, Mitchell JH: A forty-year follow-up of the Dallas bed rest and training study: the effect of age on the cardiovascular response to exercise in men. J Gerontol A Biol Sci Med Sci 2009;64:293299.

23 Perhonen MA, Franco F, Lane LD, Buckey JC, Blomquist CG, Zerwe KH JE, Peshok RM, Weatherall PT, Levine BD: Cardiac atrophy after bed-rest and space flight. J Appl Physiol 2001;91:645-653.

24 Prasad A, Popovic ZB, Arbali-Zadeh A, et al: The effects of aging and physical activity on Doppler measures of diastolic function. Am J Cardiol 2007;99:1629-1636.

25 Prasad A, Levine BD: Aging and diastolic heart failure; in Klein A, Garcia M (eds): A Clinical Approach to Diastolic Heart Failure. St. Louis, GW Medical Publishing, 2008, chapter 30, pp 385-400.

26 Muller-Delp JM, Spiers SA, Ramsey MW, Delp MD: Aging impairs endothelium-dependent vasodilation in rat skeletal muscle arterioles. Am J Physiol Heat Circ Phys 2002; 283:1662-1672.

27 Delp MD: Arterial adaptations in microgravity contribute to orthostatic tolerance. J Appl Physiol 2007;102:836.

-28 Arbab-Zadeh A, Dijk E, Prasad A, et al: Effect of aging and physical activity on left ventricular compliance. Circulation 2004;110: 1799-1805.

29 Di Prampero PE, Narici MV: Muscles in space; in Fitton B, Battrick B (eds): A World without Gravity. ESA SP-1251. Noordwijk, European Space Agency, 2001, pp 69-82.

30 Fleg JL, Shapiro EP, O'Connor F, et al: Left ventricular diastolic filling performance in older male athletes. JAMA 1995:273:13711375.

31 Tesch PA, Berg HE, Bring D, Evans HJ, LeBlanc AD: Effects of 17 day spaceflight on knee extensor muscle function and size. Eur J Appl Physiol 2005;94:463-468.

32 LeBlanc AD, Schneider VS, Evans HJ, Pientok C, Rowe R, Spector E: Regional changes in muscle mass following 17 weeks of bed rest. J Appl Physiol 1992,73:2172-2178.

33 Schild HH, Heller M (eds): Osteoporose. Stuttgart, Georg Thieme, 1992.

34 Janz KF, Medema-Johnson HC, Letuchy EM, Burns TL, Gilmore JM, Torner JC, Willing M, Levy SM: Subjective and objective measures of physical activity in relationship to bone mineral content during late childhood: the Iowa Bone Development Study. Br J Sports Med 2008;42:658-663.

35 LeBlanc A, Schneider V, Shackelford L, West S, Oganov V, Bakulin A, Voronin L: Bone mineral and lean tissue loss after long duration space flight. J Musculoskelet Neuronal Interact $2000 ; 1: 157-160$.
36 Keyak JH, Koyama, AK, LeBlanc A, Lu Y, Lang TF: Reduction in proximal femoral strength due to long-duration spaceflight. Bone 2009;44:449-453.

37 Sibonga JD, Cavanagh PR, Lang TF, LeBlanc AD, Schneider VS, Shackelford LC, Smith SM, Vico: Adaptation of the skeletal system during long-duration spaceflight. Clin Rev Bone Miner Metab 2007;5:249-261

-38 Lang T, LeBlanc A, Evans H, Lu Y, Genant H, Yu A: Cortical and trabecular bone mineral loss from the spine and hip in long-duration spaceflight. J Bone Miner Res 2004;19:10061012.

39 Vico L, Chappard D, Alexandre C, Palle S, Minaire P, Riffat G, et al: Effects of a 120-day period of bed-rest on bone mass and bone cell activities in man: attempts at countermeasures. Bone Miner 1987;2:383-394.

40 Leblanc AD, Schneider VS, Evans HJ, Engelbretson DA, Krebs JM: Bone mineral loss and recovery after 17 weeks of bed rest. J Bone Miner Res 1990;5:843-850.

41 Rittweger J, Felsenberg D: Recovery of muscle atrophy and bone loss from 90 days bed rest: results from a one-year follow-up. Bone 2009:44:214-224.

42 Warden SJ, Fuchs RK: Exercise and bone health: optimizing structure during growth is key, but all is not in vain during aging. Br J Sports Med DOI:10.1136/bjsm.2008. 054866.

43 Bacabac, RG, Smit TH, Mullender MG, Dijcks SJ, van Loon JJWA: Klein-Nulend J: Nitric oxide production by bone cells is fluid shear stress rate dependent. Biochem Biophys Res Commun 2004;315:823-829.

44 Van Loon JJWA: Microgravity and mechanomics. Gravit Space Biol Bull 2007;20:318.

45 Rubin C, Turner AS, Muller R, Mittra E, McLeod K, Lin W, Qin YX: Quantity and quality of trabecular bone in the femur are enhanced by a strongly anabolic, noninvasive mechanical intervention. J Bone Miner Res 2002;17:349-357.

46 Adams GR, Caiozzo VJ, Baldwin KM: Skeletal muscle unweighting: spaceflight and ground-based models J Appl Physiol 2003; 95:2185-2201.

47 Lynch GS: Update on emerging drugs for sarcopenia - age-related muscle wasting. Expert Opin Emerg Drugs 2008;14:655-673.

48 Vernikos J: The G-Connection: Harness Gravity and Reverse Aging. Lincoln, iUniverse, 2004.

49 Trappe S, Costill D, Gallagher PM, Creer A, Peters JR, Evans H, Riley DA, Fitts RH: Exercise in space: human skeletal muscle after 6 months aboard the International Space Station. J Appl Physiol 2009;106:1159-1168.

50 Bachl N, Baron R, Tschan H, Mossaheb M, Bumba W, Hildebrand F, Knauf M, Witt M, Albrecht R, Kozlovskaya I, et al: Principles of muscle efficiency in weightlessness (in German). Wien Med Wochenschr 1993,143: 588-610. 
-51 LeBlanc A, Rowe R, Schneider V, Evans H, Hedrick T: Regional muscle loss after short duration spaceflight. Aviat Space Environ Med 1995;66:1151-1154.

52 Snijders T, Verdijk LB, van Loon LJ: The impact of sarcopenia and exercise training on skeletal muscle satellite cells. Ageing Res Rev 2009;8:328-338.

53 Booth FW, Chakravathy MV, Spangenberg EE: Exercise and gene expression: physiological regulation of the human genome through physical activity J Physiol 2002;543:399411.

54 Chakrovarthy MV, Booth FW: Eating, exercise and 'thrifty' genotypes: connecting the dots toward an evolutionary understanding of modern chronic diseases. J Appl Physiol 2004,96:3-10.

-55 Stuart CA, Shangraw RE, Peters EJ, Wolfe RR: Effect of dietary protein on bed-rest related changes in whole body-protein synthesis. Am J Clin Nutr 1990;52:509-514.

-56 Biolo G, Ciocchi B, Lebenstedt M, Barazzoni R, Zanetti M, Platen P, Heer M, Guarnieri G: Short-term bed rest impairs amino-acidinduced protein anabolism in humans. J Physiol 2004;558:381-388.

57 LeBlanc A, Lin C, Shackelford L, Sinitsyn V, Evans H, Belichenko O, Schenkman B, Kozlovskaya I, Oganov V, Bakulin A, Hedrick T, Feeback D: Muscle volume, MRI relaxation times (T2), and body composition after spaceflight. J Appl Physiol 2000;89:21582164.

- 58 Krebs JM, Schneider VS, Evans H, Kuo MC, LeBlanc AD: Energy absorption, lean body mass, and total body fat changes during 5 weeks of continuous bed rest. Aviat Space Environ Med 1990;61:314-318.

59 LeRoith D: Dyslipidemia and glucose dysregulation in overweight and obese patients. Clin Cornerstone 2007;8:38-52.
60 Mikines KJ, Richter EA, Dela F, Galbo H: Seven days of bed rest on dose-response relation between plasma glucose and insulin action on glucose uptake in leg and whole body. J Appl Physiol 1991;70:1245-1254.

61 Rubin CT, Capilla E, Luu YK, Busa B, Ceawford H, Nolan DJ, Mittal V, Rosen CJ, Pessin JE, Judex S: Adipogenesis is inhibited by brief, daily exposure to high frequency, extremely low-magnitude mechanical signals. PNAS 2007;104:17879-17884.

62 Smith SM, Zwart SR, Block G, Rice BL, Davis-Street JE: The nutritional status of astronauts is altered after long-term space flight aboard the International Space Station. J Nutr 2005;135:437-443.

63 Smith SM, Wastney ME, O'Brien KO, Morukov BV, Larina IM, Abrams SA, Davis-Street JE, Oganov V, Shackelford LC: Bone markers, calcium metabolism, and calcium kinetics during extended-duration space flight on the Mir space station. J Bone Miner Res 2005; 20:208-218.

64 Gerzer R, Heer M: Regulation of body fluid and salt homeostasis - from observations in space to new concepts on Earth. Curr Pharm Biotechnol 2005;6:299-304.

65 Leach CS, Johnson PC, Cintrón NM: The endocrine system in space flight. Acta Astronaut 1988;17:161-166

66 Pietrzyk RA, Jones JA, Sams CF, Whitson PA: Renal stone formation among astronauts. Aviat Space Environ Med 2007;78(4 suppl):9-13.

67 Horak FB: Adaptation for automatic postural responses; in Bloedel J, Ebner J, Wise S (eds): The Acquisition of Motor Behavior in Vertebrates. Cambridge, MIT Press, chapter 4, 1996.

68 Reschke MF, Bloomberg JJ, Paloski WH, Mulavara AP, Feiveson AH, Harm DL: Postural reflexes, balance control, and functional mobility with long-duration head-down bed rest. Aviat Space Environ Med 2009;80(5 suppl):45-54.
69 Paloski WH, Black FO, Reschke MF, Calkins DS, Shupert C: Vestibular ataxia following shuttle flights: effects of microgravity on otolith-mediated sensorimotor control of posture. Am J Otol 1993;14:9-17.

70 Paloski WH, Black FO, Metter EJ: Postflight balance control recovery in an elderly astronaut: a case report. Otol Neurotol 2004;25: 53-56.

71 Feiveson AH, Metter EJ, Paloski WH: A statistical model for interpreting computerized dynamic posturography data. IEEE Trans Biomed Eng 2002;49:300-309.

72 Dijk DJ, Neri DF, Wyatt JK, Ronda JM, Riel E, Ritz-De Cecco A, Hughes RT, Elliott AR, Prisk GK, West JB: Sleep, performance, circadian rhythms and light-dark cycles during two space shuttle flights. Am J Physiol 2001; 281:1647-1664.

73 Winget CM, Vernikos-Danellis J, Cronin S, Leach CS, Rambaut PC, Mack PB: Circadian rhythm asynchrony in humans during hypokinesis. J Appl Physiol 1972;33:640-645.

74 Monk TH, Kennedy SK, Rose LR, Linenger JM: Decreased human circadian pacemaker influence after 100 days in space: a case study. Psychosom Med 2001;63:881-885.

75 Silver FH, DeVore D, Siperko LM: Role of mechanophysiology in aging of ECM: effects of changes in mechanochemical transduction. J Appl Physiol 2003;95:2134-2141.

76 Ingber DE: Tensegrity-based mechanosensing from macro to micro. Prog Biophys Mol Biol 2008;97:163-179.

77 Pietramaggiori G, Liu P, Scherer SS, Kaipanen A, Prsa MJ, Mayer H, Newalder J, Alperovich $M$, Mentzer SJ, Konerding MA, Huang S, Ingber DE, Orgill DP: Tensile forces stimulate vascular remodeling and epidermal cell proliferation in living skin. Ann Surg 2007;246:896-902. 